\title{
Assessments of joint hydrological extreme risks in a warming climate in China
}

\author{
Guoyong Leng, ${ }^{a *}$ Qiuhong Tang, ${ }^{a}$ Shengzhi Huang, ${ }^{\mathrm{b}}$ Xuejun Zhang ${ }^{\mathrm{a}, \mathrm{c}}$ and Junjun Cao ${ }^{\mathrm{d}}$ \\ ${ }^{a}$ Key Laboratory of Water Cycle and Related Land Surface Processes, Institute of Geographic Sciences and Natural Resources Research, Chinese \\ Academy of Sciences, Beijing, China \\ b State Key Laboratory Base of Eco-Hydraulic Engineering in Arid Area, Xi'an University of Technology, China \\ ${ }^{\mathrm{c}}$ University of Chinese Academy of Sciences, Beijing, China \\ ${ }^{\mathrm{d}}$ College of Urban and Environmental Sciences, Central China Normal University, Wuhan, China
}

\begin{abstract}
Understanding how hydrological extremes would respond to global warming and its associated uncertainties is important for better designing mitigation and adaption strategies to cope with global change. Very few works have investigated the changes in future hydrological extremes and, especially, the more devastating joint hydrological extremes over China. In this article, two combinations of joint extremes [i.e. high runoff/high soil moisture (HRHS) and low runoff/low soil moisture (LRLS)] are designed for analysis. To derive the scenarios of hydrological conditions, the bias-corrected daily climate projections from five global circulation models (GCMs) under the historical and Representative Concentration Pathways 8.5 (RCP8.5) emission scenarios are used to drive the calibrated Variable Infiltration Capacity (VIC) model from 1951 to 2099 over China. Results show notable increase of occurrence of HRHS in Northeast China, LRLS in Northwest and South of China under $2{ }^{\circ} \mathrm{C}$ global warming. The spatial pattern of changes in joint extremes tends to remain stable with global temperature increase up to $3{ }^{\circ} \mathrm{C}$. Compared with the individual extreme risk, joint extreme are much more concentrated in Northwest and South China and the magnitude of changes is several times larger. Larger areas experiencing changes are found when using lower standards of extreme definition. Because hydrological regime may change gradually in response to climate change, the threshold derived from present regime may lead to misrepresentation of extreme risk analysis. This was demonstrated by the ten times smaller magnitude of changes when adopting the updated transient threshold representing the changing hydrological regime, thus providing a low-boundary of potential changes in extremes. Our results highlight the importance of considering the changing hydrological regime in addition to choosing various levels of threshold for extreme definition in order to cover the full range of possible extreme changes in a warming climate.
\end{abstract}

KEY WORDS climate change; hydrological extreme; China

Received 15 March 2015; Revised 17 June 2015; Accepted 18 June 2015

\section{Introduction}

Hydrological extremes in the form of droughts and wet spells have devastating impacts on the environment and social society (Below et al., 2007). With climate warming, not only the climatology but also the extreme would change (Arnell, 2003; O'Gorman and Schneider, 2009; Durack et al., 2012; Kumar et al., 2013a, 2013b). For better mitigation and adaptation strategies, decision makers require accessible and accurate information about the potential changes of hydrological extremes as well as the associated uncertainties (IPCC, 2012).

There is an extensive body of literature that documents the future climate change impact on the hydrological extremes. Most large-scale studies focus either on precipitation or soil moisture (e.g. Wang, 2005; Sheffield and Wood, 2008; Xu et al., 2009; Dai, 2012; Vidal et al., 2012;

\footnotetext{
* Correspondence to: G. Leng, Institute of Geographic Sciences and Natural Resources Research, Chinese Academy of Sciences, 11A Datun Road, Chaoyang District, Beijing 100101, China. E-mail: lenggy.11b@igsnrr.ac.cn
}

Orlowsky and Seneviratne, 2013; Trenberth et al., 2014) or runoff/streamflow related extremes (e.g. Hirabayashi et al., 2013; Arnell and Gosling, 2014; Forzieri et al., 2014; van Huijgevoort et al., 2014). The limitations of these studies are that most of them focus on one single variable of interest for analysis. In fact, traditional extreme risk assessment relying on only one variable may not accurately represent the concurrent extremes which are more devastating to the society, economy and ecosystems, and would therefore lead to misrepresentation of the extreme risks. For example, drought may be characterized by not only low streamflow but also concurrent low soil moisture conditions. Hence, it is hypothesized that information revealed by the joint hydrological extremes may not be apparent in individual extreme analysis. And a multivariate viewpoint may provide additional and new insights in extreme risk assessments especially in a warming climate (Hao et al., 2013; AghaKouchak et al., 2014). Despite this, analysis of joint hydrological extremes is scare and future joint hydrological extreme risks with climate warming are rarely investigated. 
Furthermore, most of previous studies investigated individual extreme changes on fixed future time periods (e.g. 2020s, 2050s or 2080s), making it difficult to compare the results as they are conducted under a wide range of scenarios. In fact, what is more relevant to policy maker is a complete picture of how regional impacts might accrue with specific global warming magnitudes such as the $2^{\circ} \mathrm{C}$ limit as suggested by the European Union (Randalls, 2010).

In extreme events analysis, an important issue is the determination of extreme definition. Among various existing approaches, threshold methods (Hisdal et al., 2001; Lorenzo-Lacruz et al., 2013) are gaining increasing popularity. By this approach, extreme events are defined as occurring when the value of variable of interest is less than a given threshold. Most previous studies on large-scale future hydrological extremes (e.g. drought/floods) have applied the so-called fixed threshold method (e.g. Hirabayashi et al., 2013; Arnell and Gosling, 2014; Dankers et al., 2014; Prudhomme et al., 2014). Typically, characteristics of extremes in the 21 st century are identified by using the threshold derived from the fixed historical period (e.g. 1971-2000). However, this stationary approach ignored the gradual change of hydrological regime in response to climatic changes as predicted by global climate models (GCMs) (Durack et al., 2012). In fact, the dry/wet conditions in the present may become normal in the future (Piontek et al., 2014) and should not be recognized as the droughts/wet spells in the future. One may argue whether or not such a stationary approach is appropriate for the assessments of extreme risk changes with climate change. Therefore, how this additional source of uncertainty associated with impact assessments would affect the extreme risk analysis deserve further investigations.

China is a developing country and more vulnerable to hydrological extremes than developed countries (Piao et al., 2010). A number of studies have reported the characteristics of historical hydrological extreme events across the country (e.g. Ma and Fu, 2003; Wang and Zhai, 2003; Zhai et al., 2005; Zou et al., 2005; Wang et al., 2011; Wu et al., 2011; Xu et al., 2014). With global warming due to increase in greenhouse gases, it is very important to investigate the future possible changes in hydrological extremes over the country in order to facilitate the adaptation and mitigation strategies. Recently, assessments of future hydrological extremes have been conducted with a focus on specific river basins using climate scenarios from previous generation [i.e. Coupled Model Intercomparison Project Phase 3 (CMIP3)] of GCMs and emission scenario [i.e. Special Reports on Emission Scenarios by the Intergovernmental Panel on Climate Change (IPCC SRES)] (Xu et al., 2009; Liu et al., 2011; Guo et al., 2013; Duan and Mei, 2014; Gu et al., 2015). Very few works, however, have investigated the future hydrological extremes at the country scale (Leng et al., 2015), and analysis of future concurrent hydrological extreme risks is especially scare across the whole country.

Here, we use the newly bias-corrected CMIP5 climate projections to drive the large-scale Variable Infiltration
Capacity (VIC) model which was well calibrated against observations (Zhang et al., 2014a) to derive the time series of future runoff and soil moisture conditions over China. We focus on the changes in joint extremes of the land surface hydrological components including runoff and soil moisture. In addition, an alternative updated threshold with a moving reference window designed to reflect the changing hydrological regime in response to climate change. By comparing with the results using traditional threshold methods, we attempt to show the uncertainties arising from the effects of the changing hydrological regime. We report the results as a function of global warming amount. In this article, Section 2 introduces the modelling method and analysis measures, Section 3 evaluate the risks of future joint extreme, and the uncertainties arising from the threshold definition and effects of changing hydrological regimes. Section 5 is for the conclusion and discussion of the main findings of this study.

\section{Data and methodology}

\subsection{Bias-corrected climate change projections}

Climate projections from five GCMs are obtained from the Inter-Sectoral Impact Model Inter-comparison Project (ISI-MIP, Warszawski et al., 2014). The climate projections are bias corrected in terms of the variability and mean of the observed climate (WATCH forcing data, Weedon et al., 2011) using the quantile-mapping approach (Hempel et al., 2013). The climate projections are provided at $0.5^{\circ} \times 0.5^{\circ}$ spatial resolution at daily time step from 1950 to 2099 and include all the necessary meteorological variables for driving land surface hydrological models. In the framework of ISI-MIP, unfortunately, only five different GCMs under the newly developed representative concentration pathways (RCPs) were bias corrected in order to provide timely assessments for the IPCC AR5 reports when this study initiated (Moss et al., 2010; Taylor et al., 2012; Collins et al., 2013). Hence, it should be noted that the full uncertainty range may not be covered and our results should only represent the potential changes by the 5 GCMs (see Table 1 for descriptions of the climate models). As found by previous studies (Tang and Lettenmaier, 2012; Gillett et al., 2013; Zhang et al., 2014b), global mean temperature (GMT) changes as an index characterizing the climate changes are independent of the emission pathways. Therefore, an example narrative assessment was presented in this study using the RCP8.5 scenarios to show the climate change impacts on the joint extremes. We acknowledge that regional climate projections may differ in terms of the magnitude of changes among the four RCPs even under the same level of GMT rise.

\subsection{Simulation of future runoff and soil moisture conditions over China}

The VIC model (Liang et al., 1994, 1996) was adopted to simulate the runoff, evapotranspiration and soil moisture. The VIC model is a physically based, semi-distributed model and is featured with the sub-grid variability of 
Table 1. Descriptions of five GCMs used in this study.

\begin{tabular}{lll}
\hline Model name & Institute acronyms & Institute full name \\
\hline GFDL-ESM2M & NOAA GFDL & NOAA Geophysical Fluid Dynamics Laboratory \\
HadGEM2-ES & MOHC (additional realizations by & Met Office Hadley Centre and Instituto Nacional de \\
IPSL-CM5A-LR & INPE) & Pesquisas Espaciais \\
MIROC-ESM-CHEM & IPSL & Institut Pierre-Simon Laplace \\
& MIROC & Japan Agency for Marine-Earth Science and \\
& & Technology, Atmosphere and Ocean Research \\
NorESM1-M & Institute (The University of Tokyo), and National \\
\hline
\end{tabular}

vegetation, soil and terrain characteristics. The VIC model has been widely applied for assessing the climate change impacts on hydrology at regional and global scales (e.g. Nijssen et al., 2001; Andreadis et al., 2005; Sheffield and Wood, 2008; Shukla and Wood, 2008).

The information of soil texture and bulk densities is derived by combining the 5-min digital global soil map by the Food and Agricultural Organization (FAO, 1998) with the World Inventory of Soil Emission Potentials database (Batjes, 1995). Vegetation types are derived from the advanced very high resolution radiometer-based global land cover classifications (Hansen et al., 2000). Six parameters, i.e. the three parameters in baseflow scheme $\left(D_{\mathrm{m}}\right.$ : the maximum velocity that can occur from the lowest soil layer, $D_{\mathrm{s}}$ : the fraction of $D_{\mathrm{m}}$ where nonlinear base flow begins, $W_{s}$ : the fraction of the maximum soil moisture of the lowest soil layer where nonlinear base flow occurs), the infiltration parameter $b$ and the second and third soil layer depths (d2, d3), were well calibrated for the ten river basins over China by optimizing the simulated streamflow against observations. Details for the model calibration and validation can be found in Zhang et al. (2014a). By using the above bias-corrected climate data, time series of daily hydrologic terms from the calibrated VIC model were produced for the period 1950-2099. We excluded the first 20-year results to eliminate the impact of initial conditions and started our analysis from 1971 to 2099.

\subsection{Analysis measures}

The 90 and $10 \%$ quantiles of monthly runoff and soil moisture in the historical period (1971-2000) are used as threshold levels for defining the extremes.

Specifically, the identification of future high runoff (HR) event is as follows:

$$
\begin{aligned}
& \operatorname{HR}(i, j, n)= \begin{cases}1, & R(i, j, n) \geq R_{x}\left(t_{0}, n\right) \\
0, & R(i, j, n)<R_{x}\left(t_{0}, n\right)\end{cases} \\
& i=1,2, \ldots 30 ; j=1,2, \ldots 12
\end{aligned}
$$

where $\operatorname{HR}(i, j, n)$ is a binary variable indicating whether a location or grid cell $(n)$ is in extreme. $i, j$ are for the year and month, respectively. $R_{x}\left(t_{0}, n\right)$ is the $x$ (e.g. 90\%) percentile threshold derived from the monthly values of the reference period (e.g. 1971-2000) centred at the year $t_{0}$ (e.g. 1985). For identification of low runoff events, the $10 \%$ percentile threshold is used.

$$
\begin{aligned}
& \mathrm{LR}(i, j, n)= \begin{cases}1, & R(i, j, n)<R_{x}\left(t_{0}, n\right) \\
0, & R(i, j, n) \geq R_{x}\left(t_{0}, n\right)\end{cases} \\
& i=1,2, \ldots 30 ; j=1,2, \ldots 12
\end{aligned}
$$

Here, $90 \%$ quantiles indicates runoff or soil moisture occurrences above the $90 \%$ quantile, while $10 \%$ quantiles denotes occurrences below the $10 \%$ quantile. To examine the sensitivity of joint extremes to the choice of threshold levels, we select the 70 and $80 \%$ quantiles for defining the above-normal condition and 30 and $20 \%$ quantiles for the below-normal conditions, respectively.

Similarly, the identification of soil moisture extreme is as follows:

$$
\begin{gathered}
\operatorname{HS}(i, j, n)=\left\{\begin{array}{l}
1, \quad S(i, j, n) \geq S_{x}\left(t_{0}, n\right) \\
0, \quad S(i, j, n)<S_{x}\left(t_{0}, n\right)
\end{array}\right. \\
i=1,2, \ldots 30 ; j=1,2, \ldots 12
\end{gathered}
$$

Two combinations of joint extremes are defined for detailed analysis: HRHS and LRLS, representing the number of concurrent high runoff/high soil moisture and low runoff/low soil moisture, respectively. In other words, joint extremes are defined as being concurrent abnormal conditions of both runoff and soil moisture. The identification of joint extremes is as follows:

$$
\begin{aligned}
& \operatorname{HRHS}(i, j, n)= \begin{cases}1, & \operatorname{HR}(i, j, n)=1 \text { and } \operatorname{HS}(i, j, \mathrm{n})=1 \\
0, & \operatorname{HR}(i, j, n)=0 \text { or } \operatorname{HS}(i, j, \mathrm{n})=0\end{cases} \\
& i=1,2, \ldots 30 ; j=1,2, \ldots 12
\end{aligned}
$$

$$
\begin{gathered}
\operatorname{LRLS}(i, j, n)=\left\{\begin{array}{l}
1, \operatorname{LR}(i, j, n)=1 \text { and } \operatorname{LS}(i, j, n)=1 \\
0, \operatorname{LR}(i, j, n)=0 \text { or } \operatorname{LS}(i, j, n)=0 \\
i=1,2, \ldots 30 ; j=1,2, \ldots 12
\end{array}\right.
\end{gathered}
$$

It should be noted that there are some other indicators which may consider the combined hydrological 
behaviours such as the Palmer Drought Severity Index (PDSI) and Standardized Precipitation Evapotranspiration Index (SPEI) (precipitation minus potential evapotranspiration). These types of indicators are characterized by merging multiply sources of information into one integrated index. The metrics HRHS and LRLS as used in this study, however, represent the concurrence of multiply extremes. That is, various single extremes overlapped at the specified spatial-temporal scale. Furthermore, the metrics used in this study explicitly include runoff that is distinct from the meteorological drought indicators based on precipitation and temperature. Hence, the metrics used in this study are different from those multi-variable indicators. To calculate the PDSI or SPEI is not within the scope of this study because we focus on the changes in the concurrence of single extremes of land surface water component (i.e. runoff and soil moisture).

There are generally two approaches to construct future climate scenarios representing specific global mean temperature change $(\Delta \mathrm{GMT})$. Tang and Lettenmaier (2012) selected those scenarios on future time periods when a given $\Delta$ GMT was exceeded. By this, the timing of the specific $\Delta$ GMT may be different among GCMs. The other approach is generally referred to as 'pattern-scaling' through constructing the linear relationship between specific amount of climate forcing and impacts (Gerten et al., 2013; Arnell et al., 2014). This approach is usually conducted at the monthly scale and thus may neglect the effects of variability changes. Also, the derived relationship may depend on the variables selected for the construction of relationship function. In this study, we adopted the approach proposed by Tang and Lettenmaier (2012) which has been widely used in a number of climate change impact studies (e.g. Portmann et al., 2013; Haddeland et al., 2014; Schewe et al., 2014; Zhang et al., 2014b) to construct the climate scenarios associated with specific $\Delta \mathrm{GMT}$.

For each grid $n$, the total number of joint extremes in the historical and future periods associated with specific global warming amount is first calculated. Then the percentage changes are calculated as follows:

$\Delta \operatorname{HRHS}(n)$

$$
\begin{gathered}
=100 \times \frac{\sum \operatorname{HRHS}(i, j, n)-\sum \operatorname{HRHS}\left(i_{0}, j_{0}, n\right)}{\sum \operatorname{HRHS}\left(i_{0}, j_{0}, n\right)} \\
i=1,2, \ldots 30 ; j=1,2, \ldots 12
\end{gathered}
$$

$\Delta \operatorname{LRLS}(n)$

$$
\begin{aligned}
& =100 \times \frac{\sum \operatorname{HRHS}(i, j, n)-\sum \operatorname{HRHS}\left(i_{0}, j_{0}, n\right)}{\sum \operatorname{HRHS}\left(i_{0}, j_{0}, n\right)} \\
& i=1,2, \ldots 30 ; j=1,2, \ldots 12
\end{aligned}
$$

It should be noted that the changes in the frequency (number of joint extreme events) rather than the magnitudes are investigated in this study. As for the dynamical (non-stationary) threshold approach, the threshold is based on the monthly values of the previous 30-year time window (i.e. $t_{0}=i-1$ ). By this, threshold varies every year during the 21 st century. In addition, this approach adjusts to the gradual changes in the hydrological regime in response to climate change. The percent changes in the joint occurrence of extremes are calculated for each simulation, and the multi-model ensemble is used for our analysis. Uncertainty ranges/magnitudes along with the multi-model ensemble mean results were presented by using the box-diagram scheme.

\section{Results}

3.1. Regional climatic change across China under $2{ }^{\circ} \mathrm{C}$ global warming

Figure 1 shows the multi-model ensemble mean changes in annual mean temperature and precipitation over China under the backdrop of $2{ }^{\circ} \mathrm{C}$ global warming. The magnitude of changes in regional temperature exhibits an evident geographical gradient where the increment of temperature increases from South China to North China. Notably, China is primarily characterized by the increment of temperature less than $2^{\circ}$, whereas only small parts of northern and western China will experience temperature increment higher than $2^{\circ}$. Compared with temperature increment, regional disparity is significant for the precipitation response to the $2^{\circ} \mathrm{C}$ global warming. According to model projections, northwestern and northeastern China will experience an increase in precipitation by $5-10 \%$, and the largest percentage increase $(>15 \%)$ will occur in Inner-Mongolia. As for South China except for some parts of coast regions, precipitation is projected to decrease by approximately $5 \%$. The results suggest the substantial difference in regional climatic responses to the GMT rise over China. In general, Northern China has a tendency towards wetness and South China has a trend towards dryness under the background of global warming.

\subsection{Individual and joint extreme risks under $2{ }^{\circ} \mathrm{C}$} global warming

Figure 2 exhibits the occurrence changes in individual extreme events of abnormal runoff or soil moisture conditions with $2^{\circ} \mathrm{C}$ GMT increase. Figure 2(a) indicates that Northern and Northwestern China is dominated by an increasing HR (higher than 90\% quantile runoff) with the increase up to $100 \%$, whilst most of the rest parts in China is characterized by a decreasing HR with the reduction ranging from -10 to $-60 \%$. It can be observed from Figure 2(b) that China is mainly dominated by an increasing LR (lower than 10\% quantile runoff), particularly for the Northwest China in which the LR in most of areas increase by nearly $800 \%$. Large spatial transitions of percentage changes in LR events are found, mainly due to the fact that the historical climatology values is small (Figure S1b, Supporting Information) and the changes are expressed in relative term. Regarding HS (higher than 90\% quantile soil moisture) and LS (lower than 10\% quantile soil moisture) events shown in Figure 2(c) and (d), 

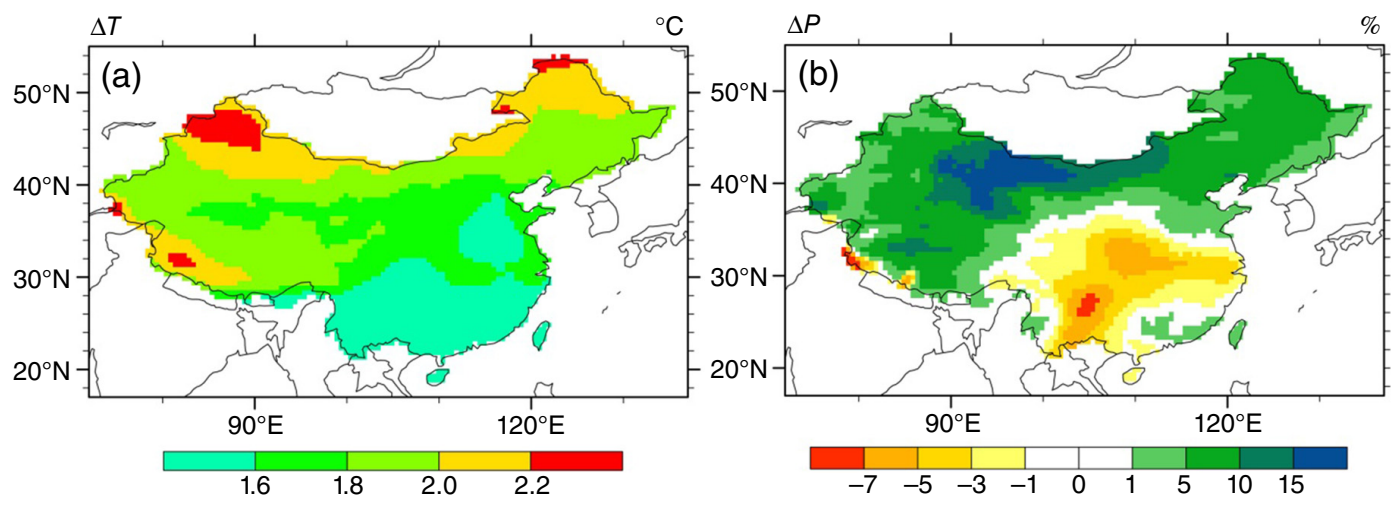

Figure 1. Changes in (a) temperature $\left({ }^{\circ} \mathrm{C}\right)$, precipitation $(\%)$ in China under $2{ }^{\circ} \mathrm{C}$ global warming.
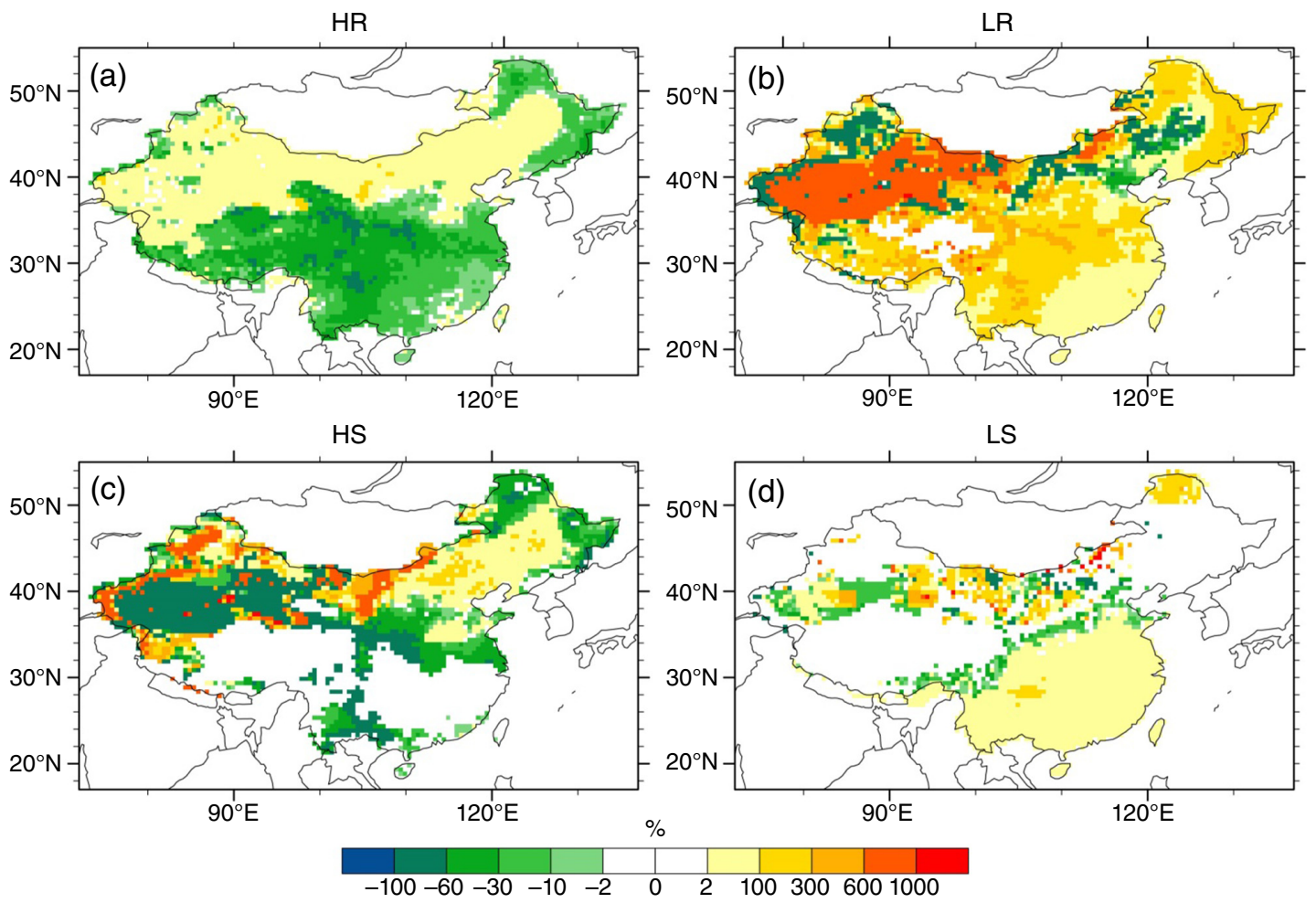

Figure 2. Changes (\%) in occurrences of individual hydrological extremes under $2{ }^{\circ} \mathrm{C}$ global warming.

respectively, their variations in Northern China are more complicated than those in Southern China. Overall, Northern China is primarily dominated by increasing HS and LS, whereas Southern China is mainly characterized by negligible changes in HS and increasing LS. On the whole, Northern China is generally dominated by increasing HR, LR, HS, and LS, while South China is generally characterized by decreasing HR and negligible changes in HS and increasing LR and LS, implying that Northern China has a tendency towards wetness and South China has a trend towards dryness, which is consistent with the finding from the climatic perspective as obtained in Figure 1(b).

Global warming would, in most cases, lead to potential increase of extremes of single variable as shown in Figure 2. It should be noted that the timing of the single variable extremes would also change with global warming. Hence, with regard to the concurrent extremes, the picture would be more complex. It is found that the land areas experiencing joint extreme are much more concentrated (Figure S2). This is due to the fact that joint extremes are representing the concurrence of multiply extremes and the probability of joint extremes should be smaller than the smallest among the multiply extremes. Figure 3 presents the changes in occurrences of joint extremes over China with $2{ }^{\circ} \mathrm{C}$ global warming. It is seen from Figure 3(a) that the HRHS (concurrent HR and soil moisture) events will be reduced by $60-100 \%$ in much of northwestern and parts of Northeastern China. The changes in the occurrence of joint extreme can be explained mathematically from the nature of the index [see the Equations (5) and (6)]. That is, changes in the frequency and/or timing of single extreme can lead to the changes in the joint extreme. Hence, given the increase of single extreme (Figure 2), the projected decrease of joint extreme are mainly due to 

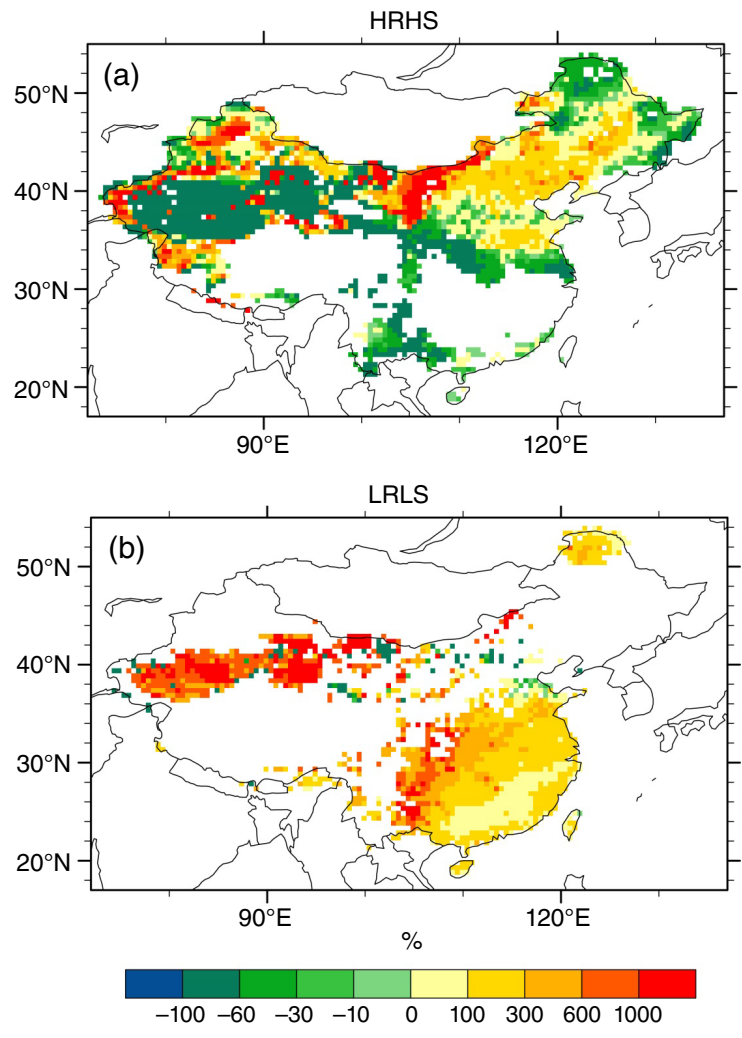

Figure 3. Changes $(\%)$ in occurrences of joint hydrological extremes under $2{ }^{\circ} \mathrm{C}$ global warming. Note that the white colours indicate the grids with no joint extreme in the reference period.

the altered timing of single extreme with global warming. Increases up to $300 \%$ are projected in North China Plain and Inner-Mongolia while no evident changes are found over South China except for small part of Southwest China. The occurrence of LRLS events (Figure 3(b)) representing the concurrent low runoff and low soil moisture conditions will increase greatly in most of the country especially in northwest and south China. Compared with the results based on individual extreme analysis (Figure 2), the magnitude of percentage occurrence changes in joint extremes is much larger in Northwest and South China For example, more than $1000 \%$ increase of joint extreme are projected in part of southern and northern China while the largest increase of single extreme ranges from 600 to $800 \%$ in part of western China. Our results suggest that traditional individual risk assessment methods based on either runoff or soil moisture condition may substantially underestimate the risk of extreme events because of ignoring the effects of relationships between the variables. Therefore, we argue that a multivariate viewpoint can provide information which cannot be revealed by individual extreme analysis and is necessary for assessing extreme events risks in a warming climate.

3.3. Response of joint extremes to different levels of global warming

In addition to the changes under $2^{\circ} \mathrm{C}$ global warming, the projected changes in joint extremes with 1 and $3{ }^{\circ} \mathrm{C}$ global warming were also calculated as shown in Figures
S3 and S4, respectively. Generally, the spatial structure of joint extremes is found to be insensitive to global warming but with the mixed responses at the regional scale in terms of the magnitude of changes. More specifically, land areas experiencing various magnitude levels of changes of HRHS events are projected to decrease with increase of GMT (Figure 4(a)). However, there are some exceptions. For example, land areas experiencing the largest changes (i.e. -100 to $-60 \%$ and $>1000 \%$ ) of HRHS events will become larger with increase of GMT. For the LRLS events presented in Figure 4(b), areas experiencing decrease of occurrences are constant with increase of GMT while the areas experiencing increase of occurrences are projected to increase linearly with GMT rise. Especially, the land areas experiencing increase more than $1000 \%$ of LRLS events will double with $\Delta$ GMT up to $3{ }^{\circ} \mathrm{C}$. These areas are generally located in the presently dry regions in northwestern and southwestern China, which is more vulnerable than eastern regions of China to climate change due to its relatively fragile economical-environmental nature. Although large inter-model spread exist, the results imply nonlinear changes of impacts along with $\Delta$ GMT with regional disparities in influence magnitudes.

\subsection{Sensitivity to the thresholds for extreme definition}

Given the fuzzy nature of extreme events, there is no universally accepted definition of extreme event. Therefore, it is of significance to use various levels of threshold to explore the sensitivity of results to the extreme definitions. Similar patterns of changes in joint extremes are found when the alternative $70 / 30 \%$ and $80 / 20 \%$ quantile were used as the extreme thresholds (figures not shown for brevity). Figure 5 shows the land areas experiencing different levels of changes in extreme events using different quantile thresholds under $2^{\circ} \mathrm{C}$ global warming. In general, land areas experiencing various levels of changes in the two combinations of extreme events will become larger if adopting lower threshold although the inter-model spread is large. That is, more land areas will experience changes in extreme events using the lower standards for investigating extremes. However, land areas experiencing the highest levels of changes (e.g. 600-100\% and $>1000 \%$ ) will decrease with lower standards. Our results suggest that the threshold definition of extremes could have a large impact on the detection of extreme events, leading to misrepresentation of extreme event changes in a warming climate.

\subsection{The effects of changing hydrological regime}

With climate warming, the dry/wet conditions in the present would be normal in the future. Using the fixed threshold based on the reference periods would, therefore, leads to misrepresentation of extreme events if not considering the hydrological regime shift. Figure 6 shows the changes in occurrences of the joint extremes using the updated thresholds, which take into account the gradual change of hydrological regime. In this approach, the threshold is derived from the monthly values of the previous 30-year period instead of the fixed historic period 

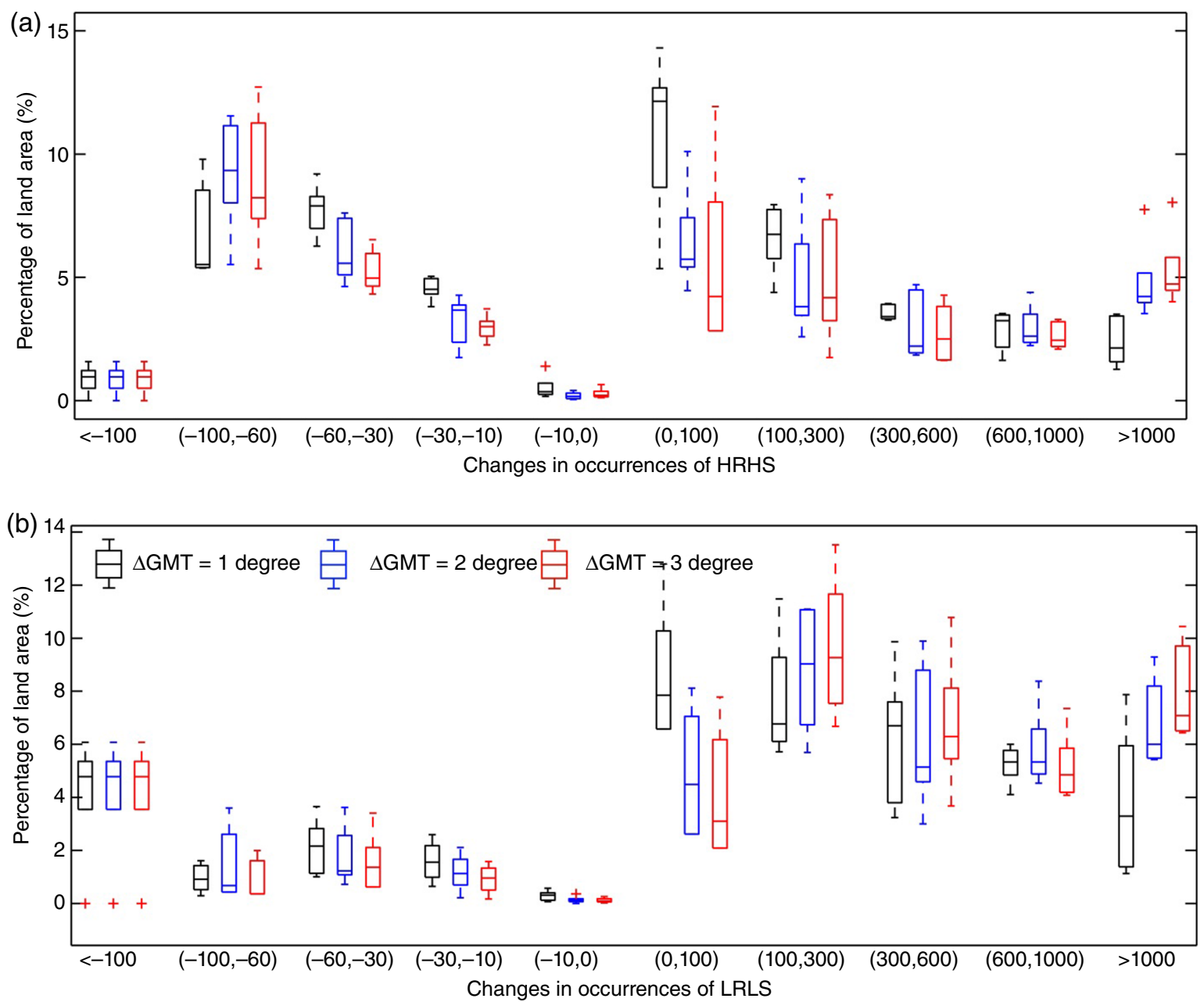

Figure 4. Changes in land areas experiencing different levels of change to global warming up to $3{ }^{\circ} \mathrm{C}$. The box edges illustrate the 25 th and 75 th percentile, the central mark is the median and the whiskers mark the 5th and 95 th percentiles.

(1971-2000). The areas experiencing changes are generally in agreement with that using the traditional fixed thresholds. However, in some regions, the change direction differs between the two methods. Importantly, changes in joint extreme risks were projected to be several times smaller than that using the traditional fixed threshold approach, indicating that an alternative extreme identification that considers adaptation to an altered hydrological regime did have a substantial influence on the projection of future extremes. This additional source of uncertainty associated with impact assessments has great implications for informing policy-makers in designing mitigation and adaption strategies to cope with climate warming. Our results suggest that the approach considering the gradual changes in hydrological regime should be applied in extreme event evaluation in order to cover the full potential impacts, thereby providing more reliable interpretation of future changes in extreme risks.

\section{Conclusion and discussions}

With global warming, increased temperatures and changes in precipitation will result in fundamental changes in the distribution of hydrological components in China, with potential changes in the hydrological extremes posing a grand challenge for water resources management. Moreover, climate change impacts are characterized with multiple dimensions. That is, impacts can occur across many dimensions of the hydrology, ecology, social- economy and etc. Hence, it is important to investigate the multi-dimensional impacts in a consistent way. Previous studies mainly used various univariate indicators representing different aspects of impacts (Arnell et al., 2014; Piontek et al., 2014) or using multi-variable based index by merging various source of information into one integrated index (e.g. PDSI, SPEI). However, changes in the concurrent (joint) extremes, which could provide new insights on the impacts, is rarely investigated in a consistent way. Here, we examined the potential changes in the occurrences of joint hydrological extremes of the land surface water components, i.e. concurrent abnormal runoff and soil moisture conditions. Hydrologic time series are derived by driving the calibrated VIC model with bias-corrected climate model outputs. The results are presented as a function of GMT change in order to evaluate the possible policy recommendations and achievable level of GMT increase. 

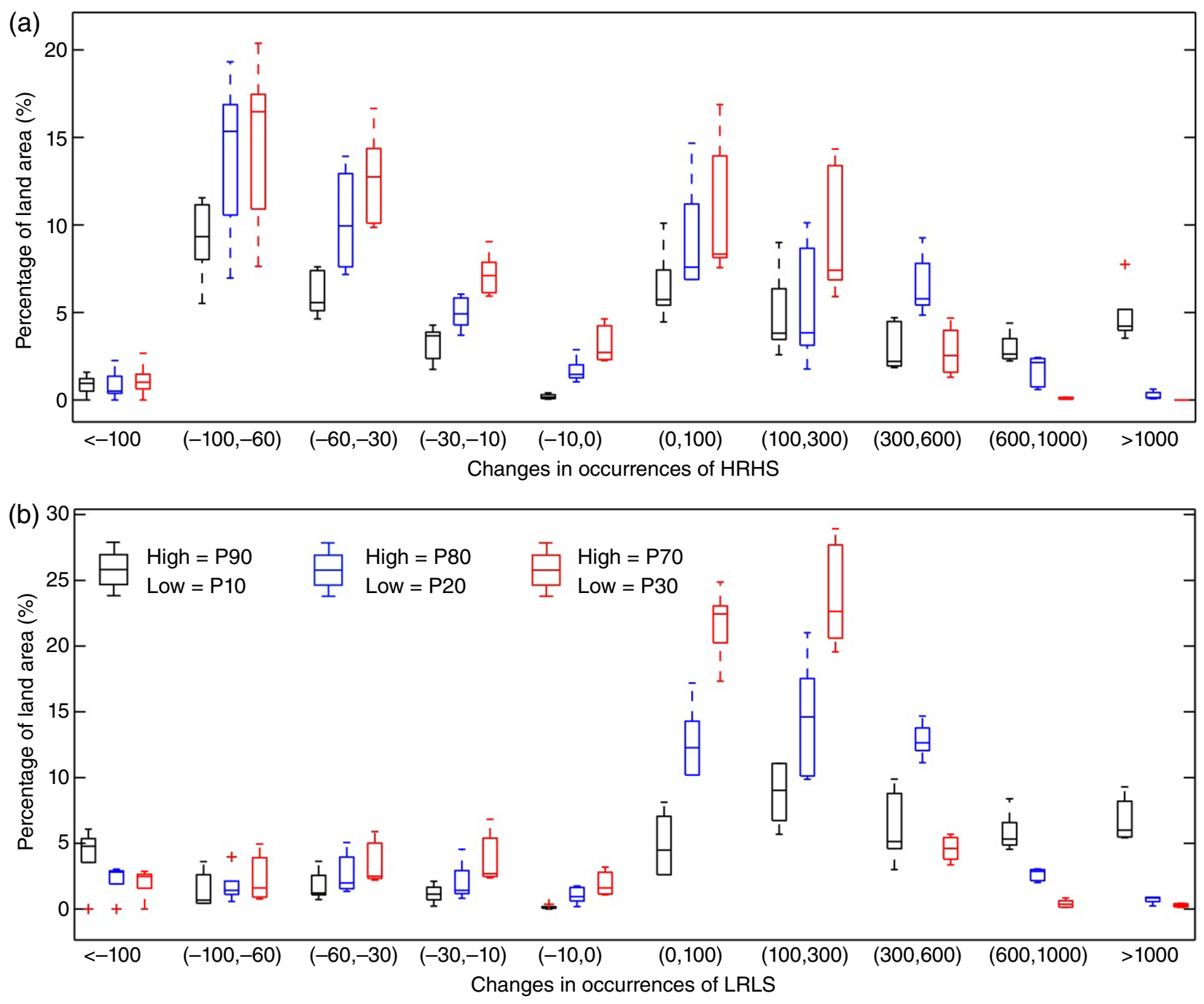

Figure 5. Sensitivity of land areas experiencing different levels of change to the definition of threshold under $2{ }^{\circ} \mathrm{C}$ global warming. The box edges illustrate the 25 th and 75 th percentile, the central mark is the median and the whiskers mark the 5 th and 95 th percentiles.

Our results show substantial changes in joint extremes over China with $2^{\circ} \mathrm{C}$ global warming. Specifically, results show large increase of occurrence of HRHS in Northeast China, LRLS in Northwest and South of China under $2{ }^{\circ} \mathrm{C}$ global warming. Moreover, the land areas experiencing the largest changes, i.e. the hotspot of climate change impacts over China, are those presently dry/wet regions in general. Notably, the magnitude of percentage occurrence changes in joint extremes is much larger in regions hit by increase of individual extremes and the land areas experiencing changes are also much more concentrated, thereby providing additional information which cannot be revealed by individual extreme analysis. It should be noted that correlations between HR and HS, and LR and LS would exist as governed by the physical hydrological process. The relationship should be similar to that between temperature and precipitation. Because of heterogeneity of land surface characteristics and complex hydrological process, time lags would occur in the occurrence of runoff extreme and soil moisture extreme. When the singe extremes overlapped (i.e. concurrence of hydrological extremes) in certain spatial-temporal scale, more devastating impacts would be caused to the humans and natural systems. With GMT rise up to $3{ }^{\circ} \mathrm{C}$, the spatial patterns of changes in the two combinations of joint extremes remain relatively stable. However, changes in land areas experiencing various levels of magnitude of changes exhibited nonlinear relationships with GMT rise. It should be noted that the VIC model did not account for the effects of $\mathrm{CO}_{2}$ concentration change, which may affect the water resource through vegetation dynamics. Land use and land cover change are also ignored. Hence, the results based on the off-line simulations should mainly represent the effects of climatic change with global warming although land use/cover change impacts were considered in CMIP5 climate outputs (Kumar et al., 2013a, 2013b).

To better inform policy maker, it is always imperative to present the uncertainties in the assessments of climate change impacts. Previous studies have shown that GCM is the largest source of uncertainty (Kay et al., 2009) followed by the emission scenarios (Maurer, 2007). Other studies argue that downscaling may have comparable 


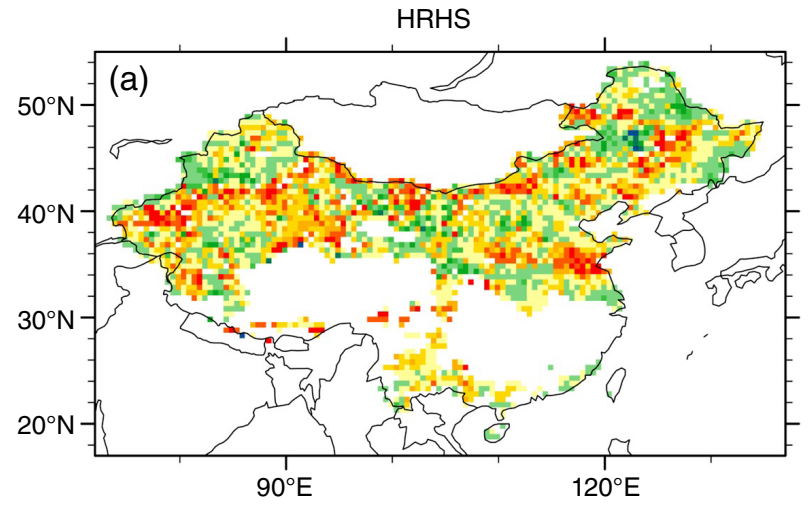

LRLS

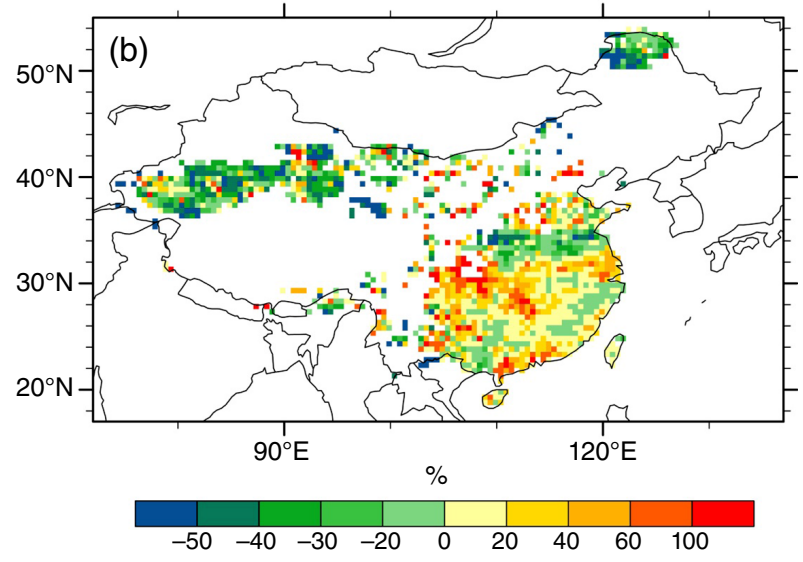

Figure 6. Changes (\%) in occurrences of joint hydrological extremes based on the transient threshold method under $2{ }^{\circ} \mathrm{C}$ global warming. Note that the white colours indicate the grids with no joint extreme in the reference period.

effects with that by GCMs (Wilby et al., 2000; Maurun et al., 2010; Chen et al., 2011; Teutschbein and Seibert, 2012). Recently, the uncertainties arising from impact models were shown to be comparable and even larger than GCMs (Haddeland et al., 2014; Pointek et al., 2014; Prudhomme et al., 2014). Nevertheless, to include all aspects of uncertainties is not feasible because no efficient way exist to handle all of them. In this article, the climate projections are bias corrected against observations (Hempel et al., 2013), and the value of them has also been well demonstrated in a number of recent studies (e.g. Dankers et al., 2014; Elliott et al., 2014; Haddeland et al., 2014; Leng and Tang, 2014; Piontek et al., 2014; Prudhomme et al., 2014; Schewe et al., 2014). Moreover, the impact model (i.e. VIC) used in this study was calibrated and validated for the ten river basins over China and was shown to match well with the observed streamflow and soil moisture (Zhang et al., 2014a, 2014b). Instead of dealing with uncertainties as discussed above, we have explored other issues in extreme risk analysis, i.e. uncertainties from the threshold level for extreme definition and the effects of changing hydrological regime.

Our results show that assessments of extreme event risks are indeed depending on the threshold of extreme definition. Compared to the results based on the $90 / 10 \%$ quantile, land areas experiencing extreme risk changes are found to become larger when using 70/30\% and 80/20\% quantiles as the thresholds. However, the spatial patterns of changes are relatively insensitive to the various levels of threshold for extreme definitions. Using the fixed threshold derived from the climatology in the historical period, the information on extreme change is apparently useful in guiding the society to mitigate the negative impacts of climate change. On the other hand, it is possible that the extremes would become normal in the future and humans and natural systems may gradually adapt to the changing regimes. Hence, compared to fixed threshold, a transient threshold for a moving reference period can provide new insights and, importantly, might be more appropriate for disaster mitigation because it reflects changes in the hydrological regime over time. Using a transient threshold assuming adaptation to long-term changes in the hydrological regime, Vidal et al. (2012) explored the use of a changing drought index for future drought in France. The areas in drought were found to be much smaller when using this transient approach compared to the traditional stationary approach. Van Huijgevoort et al. (2014) reported that stationary approach could lead to the misrepresentation of drought events and have a significant impact on the detection of drought events. By comparing the results in Figure 3, increase of joint extreme events is projected to be several time smaller as shown in Figure 6, thus providing lower bounds of possible future changes. This implies that the effects of extremes defined from the fixed historical reference may not exert the same level of impacts on the humans and natural systems in the future. In other words, the impacts of future extremes should fall somewhere between the projections in Figures 3 and 8 . This has great implications for the extreme risk analysis because most previous studies used the threshold derived from the fixed historical period. Therefore, we highlight the importance of considering the changing hydrological regime in addition to choosing various levels of threshold for extreme definition, in order to cover the full range of possible changes in extreme risks in a changing climate.

\section{Acknowledgements}

We thank the Editor and reviewers for their careful reviews and constructive comments and suggestions which led to substantial improvements in the manuscript. This work was supported by the National Basic Research Program of China (grant no. 2012CB955403) and National Natural Science Foundation of China (grant nos. 41425002 and 41171031).

\section{Supporting Information}

The following supporting information is available as part of the online article:

Figure S1. The thresholds of (a) HR, (b) LR, (c) HS and (d) LS derived from the historical period 1971-2000.

Figure S2. The total number of joint extremes in the historical period 1971-2000. Note that the white colours 
indicate the grids with no join extreme in the reference period.

Figure S3. Changes in (a) temperature $\left({ }^{\circ} \mathrm{C}\right)$, precipitation (\%) in China under $1^{\circ} \mathrm{C}$ global warming.

Figure S4. Changes in (a) temperature $\left({ }^{\circ} \mathrm{C}\right)$, precipitation $(\%)$ in China under $3{ }^{\circ} \mathrm{C}$ global warming.

\section{References}

AghaKouchak AL, Mazdiyasni CO, Farahmand A. 2014. Global warming and changes in risk of concurrent climate extremes: insights from the 2014 California drought. Geophys. Res. Lett. 41: 8847-8852.

Andreadis KM, Clark EA, Wood AW, Hamlet AF, Lettenmaier DP. 2005. Twentieth-century drought in the conterminous united states. $J$. Hydrometeorol. 6: 985-1001.

Arnell NW. 2003. Effects of IPCC SRES emissions scenarios on river runoff: a global perspective. Hydrol. Earth Syst. Sci. 7: 619-641.

Arnell NW, Gosling SN. 2014. The impacts of climate change on river flood risk at the global scale. Clim. Change, doi: 10.1007/ s10584-014-1084-5.

Arnell NW, Brown S, Gosling SN, Hinkerl J, Huntingford C, LIoyd-Hughes B, Lowe JA, Osborn T, Nicholls RJ, Zelazowski P. 2014. Global-scale climate impact functions: the relationship between forcing and impact. Clim. Change, doi: 10.1007/s10584 -013-1034-7.

Batjes NH. 1995. A Homogenized Soil Data File for Global Environmental Research: A Subset of FAO, ISRIC and NRCS Profiles. International Soil Reference and Information Center (ISRIC): Wageningen, The Netherlands.

Below R, Grover-Kopec E, Dilley M. 2007. Documenting droughtrelated disasters: a global reassessment. J. Environ. Dev. 16: 328-344.

Chen J, Brissette FP, Leconte R. 2011. Uncertainty of downscaling method in quantifying the impact of climate change on hydrology. $J$. Hydrol. 401: 190-202.

Collins M, Knutti R, Arblaster J, Dufresne JL, Fichefet T, Friedlingstein P, Gao X, Gutowski WJ, Johns T, Krinner G, Shongwe M, Tebald C, Weaver AJ, Wehner M. 2013. Long-term climate change: projections, commitments and irreversibility. In Climate Change 2013. The Physical Science Basis. Contribution of Working Group I to the Fifth Assessment Report of the Intergovernmental Panel on Climate Change, Stocker TF, Qin D, Plattner G-K, Tignor M, Allen SK, Boschung J, Nauels A, Xia Y, Bex V, Midgley PM (eds). Cambridge University Press: Cambridge, UK and New York, NY.

Dai A. 2012. Increasing drought under global warming in observations and models. Nat. Clim. Change 3: 52-58.

Dankers R, Arnell NW, Clark DB, Falloon PB, Fekete BM, Gosling SN, Heinke J, Kim H, Masaki Y, Satoh Y, Stacke T, Wada Y, Wisser D. 2014. First look at changes in flood hazard in the Inter-Sectoral Impact Model Intercomparison Project ensemble. Proc. Natl. Acad. Sci. U.S.A. 111: 3257-3261.

Duan K, Mei Y. 2014. Comparison of meteorological hydrologica and agricultural drought responses to climate change and uncertainty assessment. Water Resour. Manage. 28: 5039-5054.

Durack PJ, Wijffels SE, Matear RJ. 2012. Ocean salinities reveal strong global water cycle intensification during 1950 to 2000. Science 336: 455-458.

Elliott J, Deryng D, Müller C, Frieler K, Konzmann M, Gerten D, Glotter M, Flörke M, Wada Y, Eisner S, Folberth C, Foster I, Gosling SN, Haddeland I, Khabarov N, Ludwig F, Masaki Y, Olin S, Rosenzweig C, Ruane AC, Satoh Y, Schmid E, Stacke T, Tang WD. 2014. Constraints and potentials of future irrigation water availability on agricultural production under climate change. Proc. Natl. Acad. Sci. U.S.A. 111 3239-3244.

FAO. 1998. Digital Soil Map of the World and Derived Soil Properties. Land and Water Digital Media Series 1. Food and Agriculture Organization, CD-ROM. Rome, Italy.

Forzieri G, Feyen L, Rojas R, Flörke M, Wimmer F, Bianchi A. 2014. Ensemble projections of future streamflow droughts in Europe. Hydrol. Earth Syst. Sci. 18: 85-108.

Gerten D, Lucht W, Ostberg S, Heinke J, Kowarsch M, Kreft H, Kundzewicz ZW, Rastgooy J, Warren R, Schellnhuber HS. 2013 Asynchronous exposure to global warming: freshwater resources and terrestrial ecosystems. Environ. Res. Lett. 8: 034032.
Gillett NP, Arora VK, Matthews D, Allen MR. 2013. Constraining the ratio of global warming to cumulative $\mathrm{CO}_{2}$ emissions using CMIP5 simulations. J. Clim. 26: 6844-6858.

Gu H, Yu Z, Wang G, Wang J, Ju Q, Yang C, Fan C. 2015. Impact of climate change on hydrological extremes in the Yangtze River Basin, China. Stoch. Environ. Res. Risk Assess. 29: 693-707.

Guo et al. 2013

Haddeland I, Heinke J, Biemans H, Eisner S, Flörke M, Hanasaki N, Konzmann M, Ludwig F, Masaki Y, Schewe J, Stacke T, Tessler Z, Wada Y, Wisser D. 2014. Global water resources affected by human interventions and climate change. Proc. Natl. Acad. Sci. U.S.A. 111: 3251-3256.

Hansen MC, DeFries RS, Townshend JRG, Sohlberg R. 2000. Global land cover classification at $1 \mathrm{~km}$ spatial resolution using a classification tree approach. Int. J. Remote Sens. 21: 1331-1364.

Hao Z, AghaKouchak A, Phillips TJ. 2013. Changes in concurrent monthly precipitation and temperature extremes. Environ. Res. Lett. 8: 034014

Hempel S, FrielerK WL, Schewe J, Piontek F. 2013. A trend-preserving bias correction - the ISI-MIP approach. Earth Syst. Dyn. 4: 219-236.

Hirabayashi Y, Mahendran R, Koirala S, KonoshimaL YD, Watanabe S, KimH KS. 2013. Global flood risk under climate change. Nat. Clim. Change 3: 816-821.

Hisdal H, Stahl K, Tallaksen LM, Demuth S. 2001. Have streamflow droughts in Europe more severe of frequent? Int. J. Climatol. 21: $317-333$.

van Huijgevoort MHJ, van Lanen HAJ, Teuling AJ, Uijlenhoet R. 2014. Identification of changes in hydrological drought characteristics from a multi-GCM driven ensemble constrained by observed discharge. $J$. Hydrol. 512: 421-434.

IPCC. 2012. Summary for policymakers. In Managing the Risks of Extreme Events and Disasters to Advance Climate Change Adaptation. A Special Report of Working Groups I and II of the Intergovernmental Panel on Climate Change. Cambridge University Press: Cambridge, UK and New York, NY, 3-21.

Kay AL, Davies HN, Bell VA, Jones RG. 2009. Comparison of uncertainty sources for climate change impacts: flood frequency in England. Clim. Change 92: 41-63.

Kumar S, Lawrence D, Dirmeyer P, Sheffield J. 2013a. Less reliable water availability in the 21 st century climate projections. Earth's Future 2: 152-160.

Kumar S, Dirmeyer PA, Merwade V, DelSole T, Adams JM, Niyogi D. 2013b. Land use/cover change impacts in CMIP5 climate simulations: a new methodology and 21 st century challenges. J. Geophys. Res. 118: $6337-6353$

Leng G, Tang Q. 2014. Modeling the Impacts of Future Climate Change on Irrigation over China: Sensitivity to Adjusted Projections. J. Hydrometeor. 15: 2085-2103.

Leng G, Tang Q, Rayburg S. 2015. Climate change impacts on meteorological, agricultural and hydrological droughts in China. Glob. Planet. Change 126: $23-34$.

Liang X, Lettenmaier DP, Wood EF, Burges SJ. 1994. A simple hydrologically basedmodel of land surface water and energy fluxes for GSMs. J. Geophys. Res. 99: 14415-14428.

Liang X, Lettenmaier DP, Wood EF. 1996. One-dimensional statistical dynamic recurrentation of subgrid spatial variability of precipitation in the two-layer Variable Infiltration Capacity model. J. Geophys. Res. 101: $21403-21422$

Liu T, Willems P, Pan XL, Bao A, Chen X, Veroustraete F, Dong Q. 2011. Climate change impact on water resource extremes in a headwater region of the Tarim basin in China. Hydrol. Earth Syst. Sci. 15: $3511-3527$.

Lorenzo-Lacruz J, Mor'an-Tejeda E, Vicente-Serrano SM, L'opez-Moreno JI. 2013. Streamflow droughts in the Iberian Peninsula between 1945 and 2005: spatial and temporal patterns. Hydrol. Earth Syst. Sci. 17: 119-134.

$\mathrm{Ma} \mathrm{Z,} \mathrm{Fu} \mathrm{C.} \mathrm{2003.} \mathrm{Interannual} \mathrm{characteristics} \mathrm{of} \mathrm{the} \mathrm{surface} \mathrm{hydrological}$ variables over the arid and semi-arid areas of northern China. Glob. Planet. Change 37: 189-200.

Maurer EP. 2007. Uncertainty in hydrologic impacts of climate change in the Sierra Nevada, California under two emissions scenarios. Clim. Change 82: 309-325.

Maraun D, Wetterhall F, Ireson AM, Chandler RE, Kendon EJ, Widmann M, Brienen S, Rust HW, Sauter T, Themeßl M, Venema VKC, Chun KP, Goodess CM, Jones RG, Onof C, Vrac M, Thiele-Eich I. 2010. Precipitation downscaling under climate change. Recent developments to bridge the gap between dynamical models and the end user. Rev. Geophys. 48: RG3003. 
Moss RH, Edmonds JA, Hibbard KA, Manning MR, Rose SK, van Vuuren DP, Carter TR, Emori S, Kainuma M, Kram T, Meehl GA, Mitchell JF, Nakicenovic N, Riahi K, Smith SJ, Stouffer RJ, Thomson AM, Weyant JP, Wilbanks TJ. 2010. The next generation of scenarios for climate change research and assessment. Nature 463 : $747-756$.

Nijssen B, Schnur R, Lettenmaier DP. 2001. Global retrospective estimation of soil moisture using the Variable Infiltration Capacity land surface model, 1980-93. J. Clim. 14: 1790-1808.

O'Gorman PAO, Schneider T. 2009. The physical basis for increases in precipitation extremes in simulations of 21 st-century climate change. Proc. Natl. Acad. Sci. U.S.A. 106: 14773-14777.

Orlowsky B, Seneviratne SI. 2013. Elusive drought: uncertainty in observed trends and short- and long-term CMIP5 projections. Hydrol. Earth Syst. Sci. 17: 1765-1781.

Piao S, Ciais P, Huang Y, Shen Z, Peng S, Li J, Zhou L, Liu H, Ma Y, Ding Y. 2010. The impacts of climate change on water resources and agriculture in China. Nature 467: 43-51.

Piontek F, Müller C, Pugh TAM, Clark DB, Deryng D, Elliott J, Colón-González FJ, Flörke M, Folberth C, Franssen W, Frieler K, Friend AD, Gosling SN, Hemming D, Khabarov N, Kim H, Lomas MR, Masaki Y, Mengel M, Morse A, Neuman K, Nishina K, Ostberg S, Pavick R, Ruane AC, Schewe J, Schmid E, Stacke T, Tang Q, Tessier ZD, Tompkins AM, Warszawski L, Wisser D, Schelinhuber HJ. 2014. Multisectoral climate impact hotspots in a warming world. Proc. Natl. Acad. Sci. U.S.A. 111: 3233-3238.

Pointek et al. 2014.

Portmann FT, Döll P, Eisner S, Flörke M. 2013. Impact of climate change on renewable groundwater resources: assessing the benefits of avoided greenhouse gas emissions using selected CMIP5 climate projections. Environ. Res. Lett. 8: 024023.

Prudhomme C, Giuntoli I, Robinson EL, Clark DB, Arnell NW, Dankers R, Fekete B, Franssen W, Gerten D, Gosling SN, Hagemann S, Hannah DM, Kim H, Masaki Y, Satoh Y, Stacke T, Wada Y, Wisser D. 2014. Hydrological droughts in the 21 st century: hotspots and uncertainties from a global multi-model ensemble experiment. Proc. Natl. Acad. Sci. U.S.A. 111: 3262-3267.

Randalls S. 2010. History of the $2^{\circ} \mathrm{C}$ climate target. Wiley Interdiscip. Rev. Clim. Change 1: 598-605.

Schewe J, Heinke J, Gerten D, Haddeland I, Arnell NW, Clark DB, Dankers R, Eisner S, Fekete BM, Colón-González FJ, Gosling SN, Kim H, Liu X, Masaki Y, Portmann FT, Satoh Y, Stacke T, Tang Q, Wada Y, Wisser D, Albrecht T, Frieler K, Piontek F, Warszawski L, Kabat P. 2014. Multimodel assessment of water scarcity under climate change. Proc. Natl. Acad. Sci. 111: 3245-3250.

Sheffield J, Wood EF. 2008. Projected changes in drought occurrence under future global warming from multi-model, multi-scenario, IPCC AR4 simulations. Clim. Dyn. 31: 79-105.

Shukla S, Wood AW. 2008. Use of a standardized runoff index for characterizing hydrologic drought. Geophys. Res. Lett. 35: L02405.

Tang Q, Lettenmaier DP. 2012. 21st century runoff sensitivities of major global river basins. Geophys. Res. Lett. 39: L06403.
Taylor KE, Stouffer RJ, Meehl GA. 2012. An overview of CMIP5 and the experiment design. Bull. Am. Meteorol. Soc. 93: 485-198.

Teutschbein C, Seibert J. 2012. Bias correction of regional climate model simulations for hydrological climate-change impact studies: review and evaluation of different methods. J. Hydrol. 456: 12-29.

Trenberth KE, Dai A, van der Schrier G, Jones PD, Barichivich J, Briffa KR, Sheffield J. 2014. Global warming and changes in drought. Nat. Clim. Change 4: 17-22.

Vidal JP, Martin E, Kitova N, Najac J, Soubeyroux JM. 2012 Evolution of spatio-temporal drought characteristics: validation, projections and effect of adaptation scenarios. Hydrol. Earth Syst. Sci. 16: 2935-2955.

Wang GL. 2005. Agricultural drought in a future climate: results from fifteen global climate models participating in the Intergovernmental Panel for Climate Change's 4th Assessment. Clim. Dyn. 25: 739-753.

Wang Z, Zhai P. 2003. Climate change in drought over northern China during 1950-2000. Acta Geogr. Sin. 58: 61-68.

Wang A, Lettenmaier DP, Sheffield J. 2011. Soil moisture drought in China, 1950-2006. J. Clim. 24: 3257-3271.

Warszawski L, Frieler K, Huber V, Piontek F, Serdeczny O, Schewe J. 2014. The Inter-Sectoral Impact Model Intercomparison Project (ISI-MIP): project framework. Proc. Natl. Acad. Sci. U.S.A. 111 3228-3232.

Weedon GP, Gomes S, Viterbo P, Shuttleworth WJ, Blyth E, Österle H, Adam JC, Bellouin N, Boucher O, Best M. 2011. Creation of the WATCH forcing data and its use to assess global and regional reference crop evaporation over land during the twentieth century. $J$. Hydrometeorol. 12: 823-848.

Wilby RL, Hay LE, Gutowski WJ, Arritt RW, Takle ES, Pan Z, Leavesley GH, Clark MP. 2000. Hydrological responses to dynamically and statistically downscaled climate model output. Geophys. Res. Lett. 27: 1199-1202.

Wu Z, Lu G, Wen L, Lin CA. 2011. Reconstructing and analyzing China's fifty-nine year (1951-2009) drought history using hydrological model simulation. Hydrol. Earth Syst. Sci. 15: 2881-2894.

$\mathrm{Xu}$ Y, Xu C, Gao X, Luo Y. 2009. Projected changes in temperature and precipitation extremes over the Yangtze River Basin of China in the 21st century. Quat. Int. 208: 44-52.

Xu K, Yang D, Yang H, Li Z, Qin Y, Shen Y. 2014. Spatio-temporal variation of drought in China during 1961-2012: a climatic perspective. $J$. Hydrol. 527: 630-640, doi: 10.1016/j.jhydrol.2014.09.047.

Zhai P, Zhang X, Wan H, Pan X. 2005. Trends in total precipitation and frequency of daily precipitation extremes over China. J. Clim. 18: 1096-1108.

Zhang X, Tang Q, Pan M, Tang Y. 2014a. A long-term land surface hydrologic fluxes and states dataset for China. J. Hydrometeorol. 15 : 2067-2084.

Zhang X, Tang Q, Zhang X, Lettenmaier DP. 2014b. Runoff sensitivity to global mean temperature change in the CMIP5 models. Geophys. Res. Lett. 41: 5492-5498.

Zou X, Zhai P, Zhang Q. 2005. Variations in droughts over China: 1951-2003. Geophys. Res. Lett. 32: L04707. 